\title{
An in Vitro Study of Choline Uptake by Intestine from Neonatal and Adult Rats
}

\author{
NANCY F. SHEARD AND STEVEN H. ZEISEL \\ Departments of Pathology and Pediatrics, Nutrient Metabolism Laboratory, Nutrition-Pathology Unit, Boston \\ University School of Medicine, Boston, Massachusetts 02118
}

\begin{abstract}
We studied choline uptake by slices of adult and 10-day-old rat intestine which were exposed on their mucosal surface to radiolabeled choline. Both neonatal and adult intestine transported choline. Choline uptake was observed in duodenum, jejunum, ileum, and colon of the adult rat. In the small intestine, choline uptake consisted of two components: a saturable and a nonsaturable process. The kinetic variables for saturable transport $\left(K_{m}, V_{\max }\right)$ were not significantly different in adult and neonatal small intestine. Some of the transported choline was converted to phosphatidylcholine, glycerophosphocholine, phosphocholine, and betaine. However, most of the transported choline (79-85\%) was not metabolized within the intestinal slice during a $15-\mathrm{min}$ period. We conclude that the capacity for choline transport in the rat small intestine is present early in neonatal life. The characteristics of this transport mechanism for choline are similar in the neonate and in the adult small intestine. Neonates should therefore be able to absorb the large amounts of unesterified choline that are present in milk. (Pediatr Res 20: 768-772, 1986)
\end{abstract}

\section{Abbreviations}

KRB, Krebs' Ringer buffer containing $10 \mathrm{mM}$ glucose TLC, thin-layer chromatography

Choline (trimethyl- $\beta$-hydroxyethylammonium) is an essential nutrient for several mammalian species $(1-3)$. It is necessary for the biosynthesis of the neurotransmitter acetylcholine as well as for the formation of certain membrane phospholipids (i.e. phosphatidylcholine, sphingomyelin). Because choline contains three methyl groups it is an important contributor to the methyl-donor pool within mammals (4).

Many nutrients are required in greater amounts during periods of rapid growth. Indeed, the signs of choline deficiency are easiest to elicit in young animals (4). Milk is the sole source of nutrients for the neonate, and breast milk from humans or rats contains significant amounts of unesterified choline $(5,6)$. Serum choline concentrations in neonates of several species are four to seven times higher than in mature animals $(7,8)$. Dietary sources of choline could contribute to elevated levels of blood choline in young animals (8), but the mechanisms mediating choline transport in the developing rat intestine are not known. Nutrient transport systems (i.e. for certain amino acids and sugars) within

Received September 30, 1985; accepted April 2, 1986.

Address correspondence to Dr. Steven Zeisel, Boston University School of Medicine, 85 East Newton Street, Room M-1002, Boston, MA 02118.

Supported, in part, by grants from the National Institutes of Health (AM33163, CA2761) and from the United States Department of Agriculture (CRCR11828). N.F.S. was a Foremost-McKesson Fellow of the American Institute of Nutrition. We wish to thank John N. Udall, M.D., Ph.D. for his help and suggestions. the developing small intestine are frequently different from those characterized in the intestine of mature animals (9-13).

In the present studies, we examined the kinetics of choline uptake in the developing small intestine and compared these transport characteristics with those found in the intestine of mature animals.

\section{MATERIALS AND METHODS}

Animals. Adult, male Sprague-Dawley rats (Charles River Breeding Laboratory, Wilmington, MA), each weighing 100-125 $\mathrm{g}$, were housed in stainless steel cages. Rat Chow (Ralston Purina, St. Louis, MO; $0.16 \%$ unesterified choline by our assay) and water were given ad libitum for 1 wk prior to use in our studies. Temperature in the housing facility was $24^{\circ} \mathrm{C}$. The light cycle was $12 \mathrm{~h}$ long, 0600 to $1800 \mathrm{~h}$.

Neonatal animals used in these studies were kept with lactating dams up to the time of the experiment. Litter size was limited to 10 pups per dam. Mothers were fed rat Chow (Ralston Purina; $0.16 \%$ unesterified choline by our assay) and water ad libitum. Rat milk contained $100-300 \mu \mathrm{M}$ unesterified choline by our assay. Only male rat pups, 10-11 days old, were used in the experiments described.

Materials. ${ }^{14} \mathrm{C}-[\mathrm{N}$-methyl]-choline chloride $(55 \mathrm{mCi} / \mathrm{mmol})$, ${ }^{3} \mathrm{H}$-[N-methyl]-choline chloride $(80 \mathrm{Ci} / \mathrm{mmol}),{ }^{3} \mathrm{H}$-[methoxy]inulin $(303 \mathrm{mCi} / \mathrm{g})$, and $\left[{ }^{3} \mathrm{H}\right]$-D-glucose $(80 \mathrm{Ci} / \mathrm{mmole})$ were obtained from New England Nuclear Corporation, Boston, MA. Adenosine $5^{\prime}-\left[\gamma_{-}{ }^{32} \mathrm{P}\right]$-triphosphate (triethylammonium salt; 22 $\mathrm{Ci} / \mathrm{mmol}$ ), was purchased from Amersham, Chicago, IL. All other chemicals were purchased from Fisher Scientific, Medford, MA.

Measurement of uptake by gut slices. Adult rats were anesthetized with ether, a midline abdominal incision was made, and the small intestine was visualized. Segments taken from the area immediately distal to the end of the stomach were designated as duodenum. Jejunal segments were taken from the area whose blood supply was derived from the jejunal artery. Ileal segments were taken from the area $10 \mathrm{~cm}$ proximal to the cecum. Colonic segments were taken from the area immediately distal to the cecum. In the 10-day-old rat, segments of jejunum were collected from the small intestine from the area whose blood supply was derived from the jejunal artery.

Gut sections were removed and placed in ice-cold KRB containing $10 \mathrm{mM}$ glucose. They were cut longitudinally, rinsed with KRB, and trimmed to a length of $2 \mathrm{~cm}$. These tissue slices were supported on filter paper (Whatman no. 3) and placed in a prewarmed $\left(37^{\circ} \mathrm{C}\right)$, modified-Ussing chamber containing KRB in the bottom portion of the chamber $(11,18)$. The top of the chamber was positioned over the gut slice and clamped down. $\mathrm{KRB}$ containing choline, ${ }^{14} \mathrm{C}$-choline, ${ }^{3} \mathrm{H}$-inulin, and nonradiolabeled inulin (or ${ }^{3} \mathrm{H}$-D-glucose and D-glucose) was added to this upper chamber. A gas containing $95 \%$ oxygen and $5 \%$ carbon dioxide was bubbled through the medium throughout the 15min incubation period. 
Incubations were terminated by removing the mucosal fluid (top chamber) and by rinsing the gut slice twice with ice-cold $0.9 \%$ sodium chloride. These solutions were placed on ice and later the DPM in an aliquot of each was determined by liquid scintillation spectrophotometry. The gut slice was removed from the apparatus, trimmed to the area exposed to the incubation solution $(1.6 \times 0.4 \mathrm{~cm})$, blotted, and extracted as described below. DPM in the fluid in the bottom chamber (serosal fluid) also were determined.

Following incubation, gut tissue samples were placed in an extraction solution ( $15 \% 1 \mathrm{~N}$ formic acid in acetone) and were disrupted for $1 \mathrm{~min}$ using a sonicator (Heat Systems-Ultrasonic, Plainview, NY; Model W-255R). An aliquot of the sonicate was placed in a scintillation vial and allowed to evaporate to dryness. Scintillation fluid (Scintiverse II, Fisher Scientific) was added to the vials and the samples were counted in a liquid-scintillation counter (LKB-Wallac; Model 1211 Rack Mini-beta) for 10 min. DPM were calculated using an external ${ }^{226} \mathrm{Ra}$ source and the external standards ratio to correct the CPM values for counting efficiency.

A diluted aliquot of the protein-free supernatant was dried under vacuum (Speed-Vac Vacuum Centrifuge, Savant, Hicksville, NY; Model RT-100) and used for the determination of choline. Aliquots of the mucosal fluid and of the original test solution were similarly dried, extracted, and assayed for choline content.

Identification of choline using TLC. TLC was used to determine whether the bulk of radioactivity present in the tissue and medium at the start and end of incubations was choline. Following incubations in the presence of $100 \mu \mathrm{M}$ or $10 \mathrm{mM}$ choline, the intestinal segments were quick-frozen and then extracted using the method of Bligh and Dyer (14). The aqueous and organic phases were separated. Aliquots of the mucosal medium from before and after these incubations also were studied.

Aqueous fractions were spotted on a silica gel thin-layer plate (KPAB prechannelled silica gel HL with preadsorbent, Analtech) and developed with acetonitrile/chloroform/ethanol/0.5\% sodium chloride/acetic acid (60:15:10:15:2.5 v/v) in a continuous development chamber. Bands that cochromatographed with authentic standards were identified with Dragendorff's solution (15) and iodine vapor. These were scraped into scintillation vials, eluted in $0.4 \mathrm{~N}$ hydrochloric acid and subjected to liquid scintillation spectrophotometry. Aliquots of the organic phases were dried and counted without prior chromatography.

Choline assay. Choline was isolated using liquid cation exchange chromatography in the following manner. Dried samples were resuspended in sodium-phosphate buffer, $10 \mathrm{mM}, \mathrm{pH} 6.6$. A heptanone solution containing tetraphenylboron $(5 \mathrm{mg} / \mathrm{ml})$ was added to the sample. Tubes were mixed for $1 \mathrm{~min}$ and then spun at $-4^{\circ} \mathrm{C}$ for $10 \mathrm{~min}$ at $2500 \mathrm{rpm}$ (IEC Centrifuge PR-6000, Needham Heights, MA). An aliquot of the heptanone layer was removed and placed in a tube containing $0.4 \mathrm{~N}$ hydrochloric acid. The samples were mixed again and then subjected to centrifugation $\left(2500 \mathrm{rpm} \times 10 \mathrm{~min}\right.$ at $\left.-4^{\circ} \mathrm{C}\right)$. The heptanone layer was removed and an aliquot of the acid phase was dried under vacuum (SpeedVac, Savant Industries, Hicksville, NY).

Following heptanone extraction, choline was combined with ${ }^{32} \mathrm{P}-\mathrm{ATP}$, in a reaction catalyzed by choline kinase (choline phosphotransferase, EC 2.7.1.32). ${ }^{32} \mathrm{P}$-choline was then isolated by ion exchange chromatography (Dowex AG1x8, acetate form, 200-400 mesh; Biorad, Richmond, CA) and quantitated using liquid scintillation spectrophotometry. An internal standard of ${ }^{3} \mathrm{H}$-choline was used to correct for recovery (typically $80 \%$ ). This method is a modification of the one proposed by Goldberg and McCaman (16).

Experimental design. Choline Uptake in Adult Rat Intestine. Regional variations in choline transport were studied using segments of adult rat intestine which were collected and incubated as described above. Samples from the duodenum and colon were incubated in $\mathrm{KRB}$ solution containing $100 \mu \mathrm{M}, 1 \mathrm{mM}$, or 10 $\mathrm{mM}$ choline. Studies on jejunal and ileal tissues involved 5-10 different choline concentrations in order to more precisely characterize the kinetics of the uptake system in these tissues. Choline uptake was determined in all tissues as described previously. Choline content of both the gut segment and of the incubation medium was measured.

Kinetics of Choline Uptake in Neonatal Rat Jejunum. Segments of jejunum were removed from anesthetized rat pups. Animals (10 or 11 days old) were allowed to suckle prior to the experiment. Intestinal segments were incubated in varying concentrations of choline. Tissues were collected and analyzed in the manner previously described.

Choline Metabolism within the Proximal Small Intestine. Both adult $(150 \mathrm{~g})$ and 10 - to 11-day-old rats were allowed to feed $\mathrm{ad}$ libitum up to the time of surgery. Segments from the proximal small intestine were incubated for $15 \mathrm{~min}$ at $37^{\circ} \mathrm{C}$ in $\mathrm{KRB}$ containing $10 \mathrm{mM}$ glucose, ${ }^{3} \mathrm{H}$-choline, and either $100 \mu \mathrm{M}$ or 10 $\mathrm{mM}$ unlabelled choline. Tissues were placed into a mixture of ice cold chloroform/methanol/water $(1: 1: 1 \mathrm{v} / \mathrm{v})$ and then were disrupted using a sonicator (Heat Systems Ultrasonic, Model W225R). The resulting mixture was centrifuged at $3000 \mathrm{rpm}$ for 10 min at $4^{\circ} \mathrm{C}$ (Model PR-6000 Centrifuge, IEC Corporation). After separating the aqueous layer (methanol/water) from the organic layer (chloroform), both phases were dried under a vacuum (Savant SpeedVac) and then resuspended in a known amount of solvent. An aliquot of the organic phase was counted using liquid scintillation spectrophotometry. CPM were converted to DPM using the external channels ratio.

Aliquots of the aqueous phase were spotted on silica gel thinlayer plates (Analtech KPAB) along with internal standards of choline, phosphocholine, glycerophosphocholine, betaine, and betaine aldehyde. Chromatography was performed as described earlier.

Calculations. Specific activity of the mucosal fluid was determined by analyzing the choline content of this medium following incubation and by counting the ${ }^{14} \mathrm{C}$-label present at the end of the incubation. Purity of the ${ }^{14} \mathrm{C}$-choline was assessed by TLC.

Choline uptake by intestinal tissue was calculated using the choline DPM transported. Values were corrected by subtracting choline associated with the extracellular fluid volume (inulin space).

Statistical evaluation of data was performed using nonlinear regression analysis (Fit Function, Prophet Computer System on a Digital VAX).

\section{RESULTS}

Validity of methods. Choline and glucose uptake into slices of rat intestine (ileum) proceeded at constant rates for more than 15 min (data not shown), and these rates decreased between 30 min and $1 \mathrm{~h}$ of incubation. These data suggest that relatively brief (15 min) incubations must be used to preserve tissue viability. Values for glucose transport were similar to those reported by other laboratories (17). Slices did not deteriorate (and become permeable to large molecules) since the inulin space of the tissue remained stable $\left[7.3 \mu \mathrm{l} / \mathrm{cm}^{2}( \pm 0.4 \mathrm{SEM})\right]$ between 5 and $15 \mathrm{~min}$.

At low mucosal fluid choline concentrations, uptake of choline by ileal slices was inhibited in the presence of hemicholinium-3 [decreased from $0.49( \pm 0.04 \mathrm{SEM}) \mathrm{nmol} / \mathrm{min} / \mathrm{cm}^{2}$ in controls to $\left.0.15( \pm 0.01 \mathrm{SEM}) \mathrm{nmol} / \mathrm{min} / \mathrm{cm}^{2} ; p<0.01\right]$. When the concentration of choline in the incubation medium was $10 \mathrm{mM}$, hemicholinium-3 had no significant effect on choline transport by ileum.

During the brief 15-min incubation, little of the cholineradiolabel that was transported into gut slices was metabolized. In all experiments approximately $80 \%$ of transported radiolabel remained associated with unesterified choline (Table 1). Slices from adult and neonatal rats formed only small amounts of phosphocholine, glycerophosphocholine, phospholipids, betaine, and betaine aldehyde from radiolabeled choline. 
Choline uptake in adult rat intestine. All areas of adult rat intestine accumulated choline (Table 2). When incubated in the presence of $100 \mu \mathrm{M}$ choline, slices of small intestine (duodenum, jejunum, ileum) transported choline at similar rates $(0.34-0.39$ $\mathrm{nmol} / \mathrm{min} / \mathrm{cm}^{2}$ ). The rate of choline uptake was markedly increased when these slices were incubated in $\mathrm{KRB}$ containing 10 $\mathrm{mM}$ choline (duodenum $=4.7 \mathrm{nmol} / \mathrm{min} / \mathrm{cm}^{2}$; jejunum $=5.3$ $\mathrm{nmol} / \mathrm{min} / \mathrm{cm}^{2}$; ileum $\left.=7.3 \mathrm{nmol} / \mathrm{min} / \mathrm{cm}^{2}\right)$. Segments of rat colon transported negligible amounts of choline when incubated with $100 \mu \mathrm{M}$ choline $\left(0.08 \mathrm{nmol} / \mathrm{min} / \mathrm{cm}^{2}\right)$, but accumulated choline at rates similar to small intestine $\left(4.5 \mathrm{nmol} / \mathrm{min} / \mathrm{cm}^{2}\right)$ in the presence of $10 \mathrm{mM}$ choline.

Kinetics of choline uptake in adult and 10-day-old rat small intestine. The kinetics of choline uptake were determined in both the jejunum and ileum of adult as well as in the jejunum of 10day-rats (figs. 1 to 3 ). Choline uptake in these tissues was best described by the function:

$$
\mathrm{v}=\left[\left(\mathrm{V}_{\max \text { apparent }} \times \mathrm{C}\right) /\left(\mathrm{K}_{\mathrm{m} \text { apparent }}+\mathrm{C}\right)\right]+\mathrm{bC}
$$

where $v$ is the velocity of choline uptake $\left(\mathrm{nmol} / \mathrm{min} / \mathrm{cm}^{2}\right), \mathrm{C}$ is the choline concentration in the incubation medium (mM), and $\mathrm{b}$ is the slope of the linear component of transport.

This function represents the sum of hyperbolic and linear components of transport. In both areas of small intestine, this function fit the data well (correlation coefficient $=0.97 ; p<$

Table 1. Choline metabolism within slices of rat jejunum*

\begin{tabular}{|c|c|c|c|c|}
\hline \multirow[b]{4}{*}{ Metabolite } & \multicolumn{4}{|c|}{$\%$ of recovered radiolabel in slice } \\
\hline & & Adult & 10 day olc & \\
\hline & \multicolumn{4}{|c|}{ Choline concentration in medium } \\
\hline & $100 \mu \mathrm{M}$ & $10 \mathrm{mM}$ & $100 \mu \mathrm{M}$ & $10 \mathrm{mM}$ \\
\hline Phosphatidylcholine & $3.7 \pm 0.6$ & $4.5 \pm 0.5$ & $2.9 \pm 1.1$ & $2.7 \pm 0.7$ \\
\hline $\begin{array}{l}\text { Phosphocholine and } \\
\text { glycerophospho- } \\
\text { choline }\end{array}$ & $6.0 \pm 1.6$ & 1.4 & 11.9 & \\
\hline Choline & $85.3 \pm 2.3$ & $79.0 \pm 7.6$ & $78.5 \pm 3.9$ & $80.4 \pm 4.3$ \\
\hline $\begin{array}{l}\text { Betaine and betaine } \\
\text { aldehyde }\end{array}$ & $3.3 \pm 0.2$ & 6.9 & $9.1=$ & 11. \\
\hline \multicolumn{5}{|c|}{$\begin{array}{l}\text { * Segments of jejunum from adult and } 10 \text {-day-old animals were in- } \\
\text { cubated for } 15 \mathrm{~min} \text { in the presence of }{ }^{3} \mathrm{H} \text {-choline and either } 100 \mu \mathrm{M} \text { or } \\
10 \mathrm{mM} \text { nonradiolabeled choline as described in "Methods." Slices of } \\
\text { intestine were extracted and choline containing compounds were isolated } \\
\text { by TLC. Data are expressed as mean percent of recovered choline- } \\
\text { radiolabel } \pm \text { SEM ( } n=3 \text { per point). } \\
\quad \dagger p<0.01 \text {. } \\
\ddagger p<0.05 \text { different from adult at same choline concentration. }\end{array}$} \\
\hline
\end{tabular}

$0.0001)$. Attempts to fit the data to a single line or hyperbola failed to yield a high correlation. Values for $V_{\text {max apparent }}, K_{m \text { apparen }}$ and (b) are given in Table 3 . There were no statistically significant differences in kinetic variables describing choline transport between neonates and adults.

Intestinal slice choline concentrations during incubations. Intestinal slice choline concentrations, measured prior to incubation (time 0 ), were $100-260 \mathrm{nmol} / \mathrm{g}$ wet weight in adults and more than $350 \mathrm{nmol} / \mathrm{gm}$ in the infant (Table $4 ; p<0.05$ ). During incubation at $37^{\circ} \mathrm{C}$ in $\mathrm{KRB}$ with added choline, tissue choline concentration rose. Choline uptake occurred despite the fact that intestinal slice choline concentration was higher than mucosal fluid choline concentration in all incubations in which less than $1 \mathrm{mM}$ choline was present in the incubation medium (Fig. 4). Experiments performed in 10-day-old rats resulted in similar findings (data not shown).

\section{DISCUSSION}

We showed that choline was transported across the intestine of both adult and 10-day-old rats. In these studies, we measured

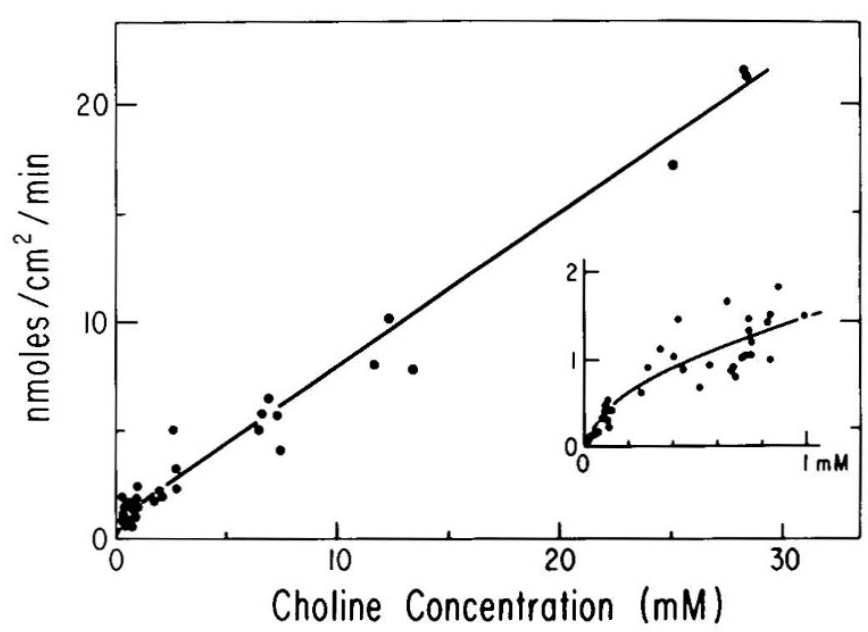

Fig. 1. Choline uptake by ileum from adult rats. Segments of ileum from adult rats were incubated for 15 min as described in "Methods." The mucosal surface of the slice was exposed to a solution containing ${ }^{3} \mathrm{H}$-inulin, ${ }^{14} \mathrm{C}$-choline, and varying concentrations of choline chloride. Net uptake of choline by tissues was calculated using tissue ${ }^{14} \mathrm{C}$-DPM after correction for extracellular space (inulin space). The inset depicts choline uptake at low concentrations of choline in the incubation medium. Seventy-one measurements of choline uptake by slices were used. The curve is the best fit to the function:

$$
\mathrm{v}=\left[\left(\mathrm{V}_{\max \text { apparent }} \times \mathrm{C}\right) /\left(\mathrm{K}_{\mathrm{m} \text { apparent }}+\mathrm{C}\right)\right]+\mathrm{bC} \text {. }
$$

Table 2. Choline uptake into slices of intestine from adult rats $\left(\mathrm{nmol} / \mathrm{min} / \mathrm{cm}^{2}\right)^{*}$

\begin{tabular}{ccccc}
\hline $\begin{array}{c}\text { Choline in } \\
\text { mucosal fluid }\end{array}$ & Duodenum & Jejunum & Ileum & Colon \\
\hline $100 \mu \mathrm{M}$ & $0.34 \pm 0.03(3)$ & $0.36 \dagger$ & $0.39 \pm 0.04(7)$ & $0.08 \pm 0.01(3)$ \\
$1 \mathrm{mM}$ & $0.94 \pm 0.04(3)$ & $1.30 \pm 0.13(5)$ & $1.91 \pm 0.23(5)$ & $0.47 \pm 0.08(3)$ \\
$10 \mathrm{mM}$ & $5.30 \pm 1.30(3)$ & $4.70 \pm 0.50(3)$ & $7.30 \ddagger$ & $4.50 \pm 0.50(3)$ \\
\hline
\end{tabular}

* Segments of intestine from adult rats were incubated for $15 \mathrm{~min}$ as described in "Methods." The mucosal surface of the slice was exposed to a solution containing ${ }^{3} \mathrm{H}$-inulin, ${ }^{14} \mathrm{C}$-choline, and varying concentrations of choline chloride. Net uptake of choline by tissues was calculated using tissue ${ }^{14} \mathrm{C}$-DPM after correction for extracellular space (inulin space). Data are expressed as mean rate of choline transport \pm SEM. Number of animals used per data point is indicated in parentheses.

$\dagger$ In this tissue we did not measure choline transport precisely at $0.1 \mathrm{mM}$ choline. For the purpose of comparison we extrapolated from the data obtained at other, similar, concentrations (data from Fig. 2).

$¥$ In this tissue we did not measure choline transport precisely at $10 \mathrm{mM}$ choline. For the purposes of comparison we extrapolated from the data obtained at other, similar, concentrations (data from Fig. 1). 


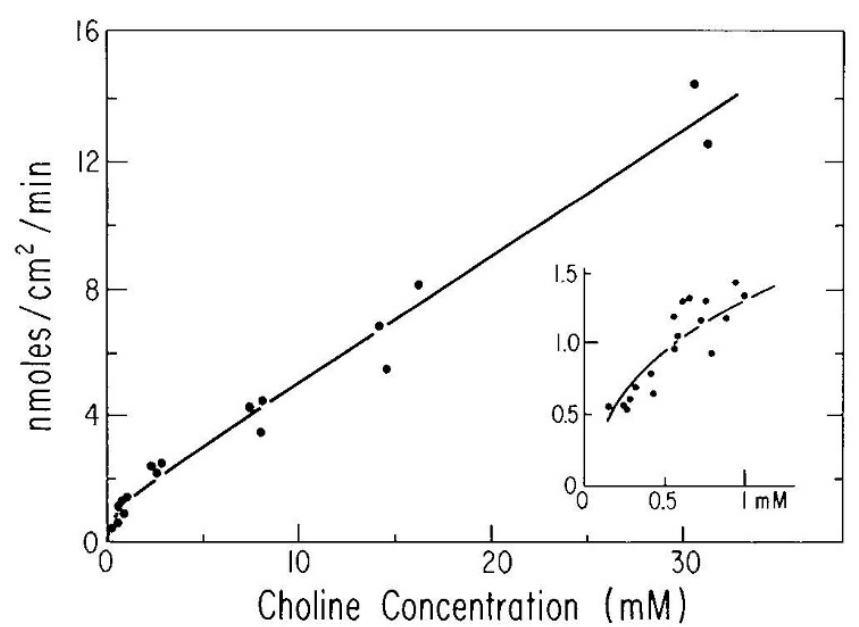

Fig. 2. Choline uptake by jejunum from adult rats. Segments of jejunum from adult rats were incubated for $15 \mathrm{~min}$ as described in "Methods." The mucosal surface of the slice was exposed to a solution containing ${ }^{3} \mathrm{H}$-inulin, ${ }^{14} \mathrm{C}$-choline, and varying concentrations of choline chloride. Net uptake of choline by tissues was calculated using tissue ${ }^{14} \mathrm{C}$ DPM after correction for extracellular space (inulin space). The inset depicts choline uptake at low concentrations of choline in the incubation medium. Thirty-four measurements of choline uptake by intestinal slices were used. The curve is the best fit to the function:

$$
\mathrm{v}=\left[\left(\mathrm{V}_{\max \text { apparent }} \times \mathrm{C}\right) /\left(\mathrm{K}_{\mathrm{m} \text { apparent }}+\mathrm{C}\right)\right]+\mathrm{bC} \text {. }
$$

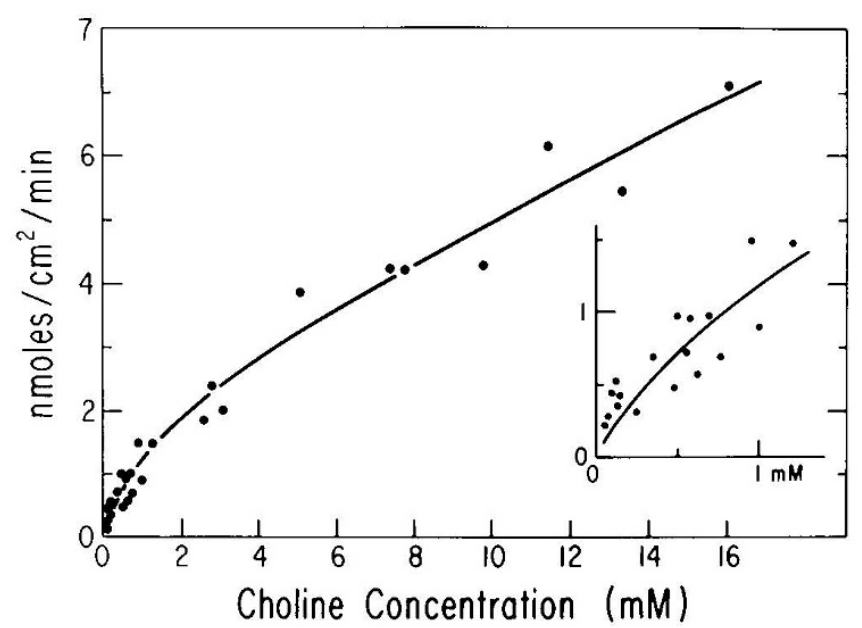

Fig. 3. Choline uptake by jejunum from 10-day-old rats. Segments of jejunum from 10-day-old rats were incubated for $15 \mathrm{~min}$ as described in "Methods." The mucosal surface of the slice was exposed to a solution containing ${ }^{3} \mathrm{H}$-inulin, ${ }^{14} \mathrm{C}$-choline, and varying concentrations of choline chloride. Net uptake of choline by tissues was calculated using tissue ${ }^{14} \mathrm{C}$ DPM after correction for extracellular space (inulin space). The inset depicts choline uptake at low concentrations of choline in the incubation medium. Thirty one measurements of choline uptake by intestinal slices were used. The curve is the best fit to the function:

$$
\mathrm{v}=\left[\left(\mathrm{V}_{\max \text { apparent }} \times \mathrm{C}\right) /\left(\mathrm{K}_{\mathrm{m} \text { apparent }}+\mathrm{C}\right)\right]+\mathrm{bC} \text {. }
$$

the uptake of choline from the lumen (mucosal fluid) to the cellular components of the tissue slice and from the lumen to the paracellular space. We did not attempt to measure transport through the enterocyte to the blood. Thus, we characterized only the initial phase of the multiple-step process of choline absorption. We showed that most of the radiolabel that accumulated within the tissue slice was in the form of choline. This supports
Table 3. Kinetic data from choline uptake studies*

\begin{tabular}{llll}
\hline \multicolumn{1}{c}{ Variable } & Adult ileum & Adult jejunum & \multicolumn{1}{c}{$\begin{array}{l}\text { Neonatal } \\
\text { jejunum }\end{array}$} \\
\hline $\mathrm{V}_{\max \text { apparent }}\left(\mathrm{nmol} / \mathrm{min} / \mathrm{cm}^{2}\right)$ & $0.9 \pm 0.04$ & $1.1 \pm 0.27$ & $2.1 \pm 0.12$ \\
$\mathrm{~K}_{\mathrm{m} \text { apparent }}(\mu \mathrm{M})$ & $0.2 \pm 0.03$ & $0.3 \pm 0.14$ & $1.3 \pm 0.18$ \\
$\mathrm{~b}\left(\mathrm{nmol} / \mathrm{min} / \mathrm{cm}^{2}\right)$ & $0.7 \pm 0.01$ & $0.4 \pm 0.01$ & $0.3 \pm 0.01$ \\
Correlation coefficient & 0.971 & 0.984 & 0.974 \\
$p$ regression & 0.0001 & 0.0001 & 0.0001 \\
\hline
\end{tabular}

* Kinetic constants were determined using nonlinear regression analysis to the function:

$$
\mathrm{V}=\left[\left(\mathrm{V}_{\text {max apparent }} \times \mathrm{C}\right) /\left(\mathrm{K}_{\mathrm{m} \text { apparent }}+\mathrm{C}\right)\right]+\mathrm{bc}
$$

The data used are those presented in Figures 1 to 3. Results are expressed as mean \pm SEM. There was no significant difference between variables in the adult and neonatal jejunum.

Table 4. Choline concentration in slices of intestinal tissue*

\begin{tabular}{lc}
\hline \multicolumn{1}{c}{ Tissue wt } & Choline (nmol/g wet) \\
\hline Adult ileum $(n=35)$ & $108 \pm 9$ \\
Adult jejunum $(n=28)$ & $257 \pm 14$ \\
Adult duodenum $(n=3)$ & $190 \pm 47$ \\
10-day-old jejunum $(n=41)$ & $359 \pm 29 \dagger$ \\
\hline
\end{tabular}

* Slices of intestine were rapidly extracted in ice-cold $15 \%$ formic acid in acetone and were immediately homogenized. Choline was assayed using the radioenzymatic technique described in "Methods." Data are expressed as mean \pm SEM.

$\dagger p<0.05$ different from adult jejunum.

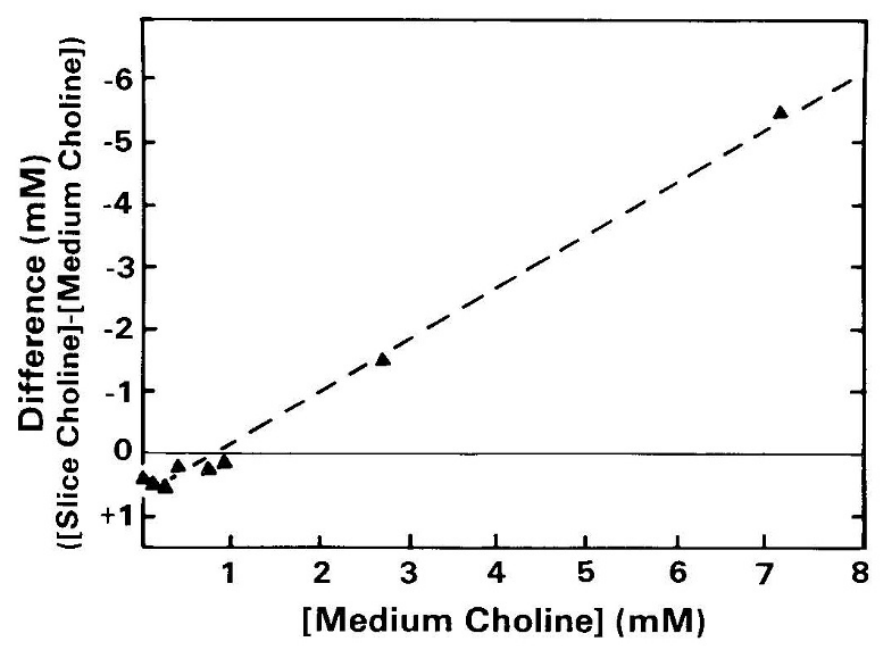

Fig. 4. Difference in choline concentration between gut slice and incubation medium. Segments of rat ileum were incubated for $15 \mathrm{~min}$ as described in "Methods." The mucosal surface of the slice was exposed to a solution containing ${ }^{3} \mathrm{H}$-inulin, ${ }^{14} \mathrm{C}$-choline and varying concentrations of choline chloride. The difference in choline concentrations was calculated as:

$$
\text { [slice choline] - [medium choline] }
$$

A positive value for this difference indicates that the concentration of choline within the gut slice was higher than was present in the bathing medium, and that any uptake of choline occurred uphill with the concentration gradient. Data presented are the mean of data from eight different choline concentrations ( $n=5-9$ per concentration). All values differ from zero, $p<0.05$ by one-way analysis of variance and Tukey test.

our contention that measurements of flux of radiolabel can be used to calculate choline uptake. The in vitro method used in these studies was a modification of that used by Schultz and Curran (18), by Cooke and Dawson (11), and by Kuczler et al. 
(19). We established that this method was best suited to short term $(15 \mathrm{~min})$ studies when transport rates for glucose and choline proceed linearly with time, and when tissue integrity is maintained (as measured by exclusion of inulin).

In any in vitro system it is impossible to obtain true values for $\mathrm{V}_{\max }$ and $\mathrm{K}_{\mathrm{m}}$ because of unstirred water layers over the intestinal surface of the gut slice (20). Thus, we report apparent, rather than true, kinetic values. The apparent affinity constants that we report can be converted to true constants based on complex calculations using known dimensions for the effective thickness and surface area of the unstirred layer (20). We attempted to minimize the unstirred water layer effects by delivering the aerating gas near the surface of the slice and bubbling it through the mucosal fluid. However, the concentration of choline will always be higher at the aqueous-membrane interface (20). Any differences between choline uptake by adult and neonatal intestine due to in vivo effects of an unstirred water layer should have been reflected in our in vitro studies.

Choline transport by the intestine has been described previously in the adult hamster, rat, guinea pig and chick $(19,21,22)$. Within the small intestine of these species, choline transport occurred by both a saturable and a nonsaturable process. Our data from all areas of the small intestine support that this is true in the adult rat. At low lumenal choline concentrations, a saturable transport mechanism predominated, while the nonsaturable mechanism became important at high lumenal choline concentrations. In addition, we showed, for the first time, that choline transport mechanisms exist in neonatal rat intestine. As in the adult rat, data regarding the choline concentration of jejunal segments from neonatal animals suggests that, at low choline concentrations, uptake by the saturable transport system occurs against a concentration gradient, implying an energy-requiring process. We observed that the choline concentration in jejunal slices was higher in neonates than in adults. This difference might be caused by the high blood choline concentrations of the neonate $(7,8)$. The mucosal surface area/ $\mathrm{cm}^{2}$ intestine is smaller in the jejunum of neonates versus adults (23), therefore, neonatal intestine had greater capacity for choline transport per surface area. Differences in electrical potential across the mucosa might influence choline transport, but we did not address this directly.

In summary, we have shown that neonatal intestine is capable of absorbing choline. Choline transport occurs via two mechanisms - a saturable process that has kinetic properties similar to that observed in adult small intestine and a nonsaturable process (probably diffusion). This finding is important because the diet (milk) is a necessary source of the choline needed by the neonate for normal growth and development.
Acknowledgment. The authors thank John N. Udall, M.D., Ph.D. for his help and suggestions.

\section{REFERENCES}

1. Deeb SS, Thornton PA 1959 The choline requirement of the chick. Poultry Sci 38:1198-1201

2. Dutra FR, McKibben JM 1945 The pathology of experimental choline deficiency in dogs. J Lab Clin Med 30:301-311

3. Handler P, Bernheim F 1949 Choline deficiency in the hamster. Proc Soc Exp Med 72:569

4. Zeisel SH 1981 Dietary Choline: Biochemistry, physiology, and pharmacology. Ann Rev Nutr 1:95-121

5. Zeisel SH, Char D, Sheard NF 1986 Choline, phosphatidylcholine and sphingomyelin in human and bovine milk, and infant formulas. J Nutr 116:50 58

6. Nayman R, Thomson ME, Scriver CE, Clow CL 1979 Observations on the composition of milk substitute products for treatment of inborn errors of amino acid metabolism. Comparisons with human milk. Am J Clin Nutr 32:1279-1289

7. Zeisel SH, Epstein M, Wurtman RJ 1980 Elevated choline concentrations in neonatal plasma. Life Sci 26:1827-1831

8. Zeisel SH, Wurtman RJ 1981 Developmental changes in rat blood choline concentration. Biochem J 198:565-570

9. Fitzgerald JF, Reiser S, Christian PA 1971 Developmental pattern of sugar and amino acid transport in the postnatal rat small intestine. Pediatr Res 5:698703

10. Younoszai MK, Komnick K 1982 Maturation of the small intestine: absorption of L-valine in rats. Pediatr Res 16:756-760

11. Cooke HJ, Dawson DC 1978 Transport characteristics of isolated newborn rabbit ileum. Am J Physiol 234:E257-E261

12. Cooke HJ, Pfankuche L, Cooke AR 1980 Tryptophan transport by isolated newborn rabbit jejunum. Am J Physiol 239:G306-G310

13. Udall JN, Pang K, Fritze L, Kleinman R, Walker WA 1982 Development of gastrointestinal mucosal barrier: $\mathrm{I}$. The effect of age on intestinal permeability to macromolecules. Pediatr Res 16:756-760

14. Bligh EG, Dyer WJ 1959 A rapid method of total lipid extraction and purification. Can J Biochem Physiol 37:911-917

15. Lowenstein JM 1969 Choline-containing phospholipids-Dragendorff test. In: Lowenstein JM (ed) Methods of Enzymology. Academic Press, New York, p 54

16. Goldberg AM, McCaman RE 1973 The determination of picomole amounts of acetylcholine in mammalian brain. J Neurochem 20:1-8

17. Hopfer U, Nelson K, Perroto J, Isselbacher K 1973 Glucose transport in isolated brush border membrane from rat small intestine. $\mathbf{J}$ Biol Chem 248:25-32

18. Schultz SG, PF Curran 1970 Coupled transport of sodium and organic solutes. Physiol Rev 50:637-718

19. Kuczler FJ, Nahrwold DL, Rose RC 1977 Choline influx across the brush border of the guinea pig jejunum. Biochim Biophys Acta 465:131-137

20. Thomson ABR 1979 Limitations of Michaelis-Menten kinetics in presence of intestinal unstirred layers. Am J Physiol 236:E701-709

21. Sanford PA, Smyth DH 1971 Intestinal transport of choline in the rat and hamster. J Physiol 215:769-778

22. Herzberg GR, Lerner J 1973 Intestinal absorption of choline in the chick. Biochim Biophys Acta 307:234-242

23. Pang KY, Bresson JL, Walker WA 1983 Development of the gastrointestinal mucosal barrier. Biochim Biophys Acta 727:201-208 